\title{
Management of double hand amputees with Krukenberg procedure: An option in Nepal
}

\author{
K.C. BR., Chand P., Thapa BB., Joshi A. \\ Shree Birendra Hospital, Chhauni, Kathmandu
}

\begin{abstract}
BACKGROUND : For the last 14 years, Nepal has been struggling with armed conflict in which civilian population have also been the victims- targeted or accidental. Mine blast is the major cause of severe injuries involving multiple systems, bilateral crush injuries of the extremities and severe soft-tissue lacerations. To the victims with bilateral hand amputation or one hand amputation with severely crushed non-functional other hand, rehabilitation and performance regarding activities of daily living (ADL) is a huge problem. Krukenberg procedure, where radius and ulna are separated and a pincer like grasp is created, was considered to restore manual dexterity in this group.
\end{abstract}

METHODS: From August 2001 to April 2007, we carried out the Krukenberg procedure on a group of double hand amputees and single hand amputee with severely crushed or partial amputation of the other hand. The procedure was initially carried out on two double hand amputees to assess the functional result and acceptability by the patient. The procedure was carried out at least 3 months after the amputation in all cases. Post-procedure the patients were rehabilitated by physiotherapist for grip strength and performance of Activities of daily living, ADL (i.e. feeding, personal hygiene, dressing and manual dexterity).

RESULTS: Five Krukenberg procedures were performed on three patients: all three were males with mean age of 25 years. Two had double hand amputation and one had single hand amputation with severely crushed other hand with ray amputations. All three patients at three months follow-up could perform ADL by themselves.

CONCLUSIONS: The Krukenberg procedure is a surgical option for double hand amputees in a poor country like Nepal.

KEYWORDS: Krukenberg procedure, bilateral hand amputee, ADL

\section{INTRODUCTION}

Nepal, a small Himalayan hilly country is situated in between two big countries, India and China with a population of 25 million. The country was struggling with armed internal conflict for the last 14 years when Maoist ideology group took up armed struggle. During the first six years, civilians and police force were the main targets. From 2001, Nepalese army got involved in the conflict.

Shree Birendra Hospital, Chhauni, being the only tertiary level Military Hospital in the country provided medical services to all combat victims that were brought in from the security forces (army, armed police and police), civilians and Maoists. The hospital provided services to almost 3,400 combat victims.
The types of injuries varied from blunt injury, cut injuries with sharp cutting knives, gunshot and mine blast injuries where severe soft tissue laceration, multisystem involvement, auto-amputation of extremities are common findings. Almost $60 \%$ of all the victims treated in this center were due to mine blast and the extremity involvement was $58 \%$. Most of the explosive devices used by maoist were IEDS (Improvised Explosive Devices like Sutali, Bucket, and Pressure Cooker bombs, filled with explosive powder along with nails, iron rods, glass pieces etc.) which were notorious in inflicting severe body damage. (Fig 1) 


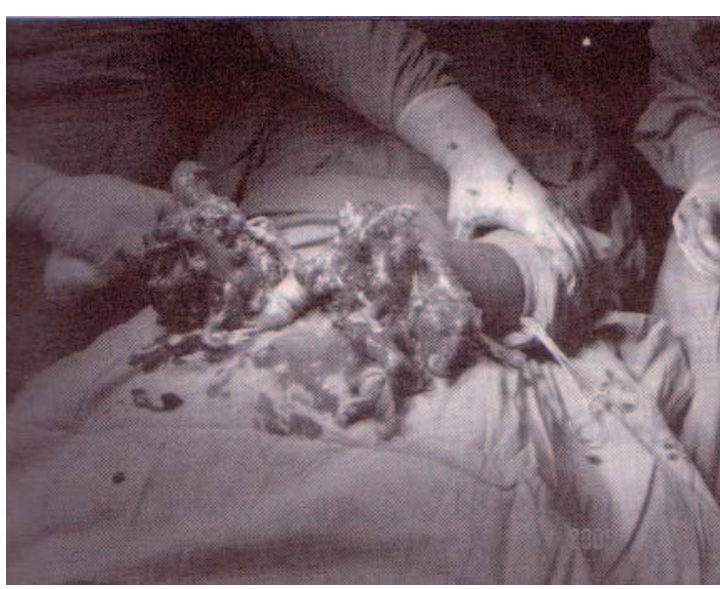

Fig 1.Severly crushed forearms

Quite a number of civilians have been the victims of stray explosive devices which has been a problem to the country because no body knows about their location. Children were the main victims of these stray explosive devices.

Most lower extremity amputees do good with prosthesis and regain fairly good degree of self sufficiency. Loss of one hand can be compensated by exclusive use of the other hand. The concern of amputees of both hands is the loss of touch and other sensations besides the inability to perform activities of daily living (ADL); and feel themselves as burden to the family and are in a state of depression. ${ }^{1,2}$

Herman Krukenberg, a German army Surgeon, developed the Krukenberg procedure in 1917. ${ }^{3,4}$ In this operation the two forearm bones are separated creating a pincer tike grasp that gives the patient good pinch, grip with useful sensibility. ${ }^{4}$ The prerequisite to perform this procedure is the forearm stump should be longer than $10 \mathrm{~cm}$ (as measured from the tip of olecranon) and the pronator teres muscle is to be outlined and preserved because it is the most important adductor of both bones. ${ }^{2,5}$

\section{MATERIALS AND METHODS}

The operations were carried out under general anesthesia and supra-clavicular regional anesthesia. Longitudinal skin incisions were made on volar and dorsal aspects of the forearm with a triangular flap dorsally for the web. (Figs 2-5)
MANAGEMENT OF DOUBLE HAND AMPUTEES WITH KRUKENBERG PROCEDURE, K.C.BR; Chand P; Joshi A; Thapa BB; Joshi A

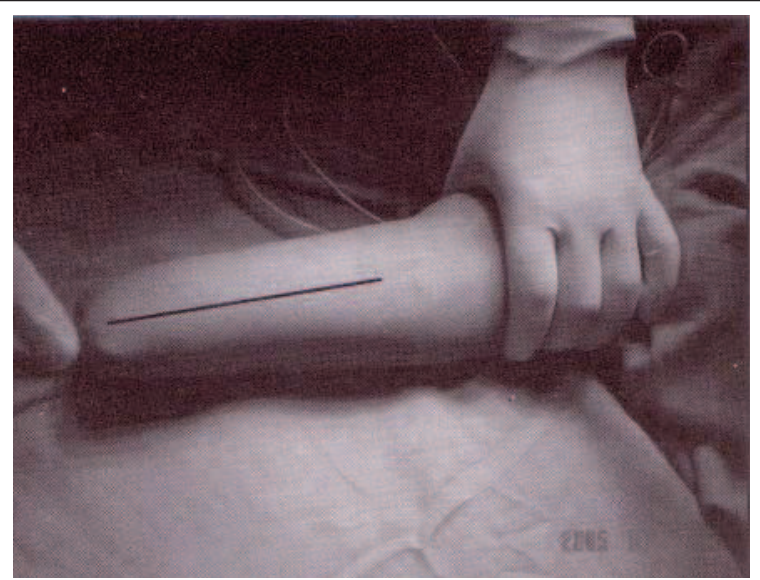

Fig. 2. Volar incision

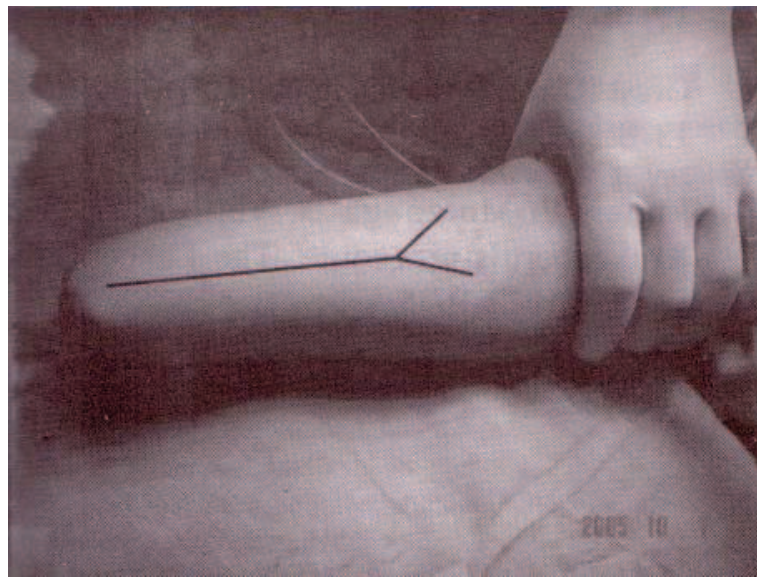

Fig. 3. Dorsal incision

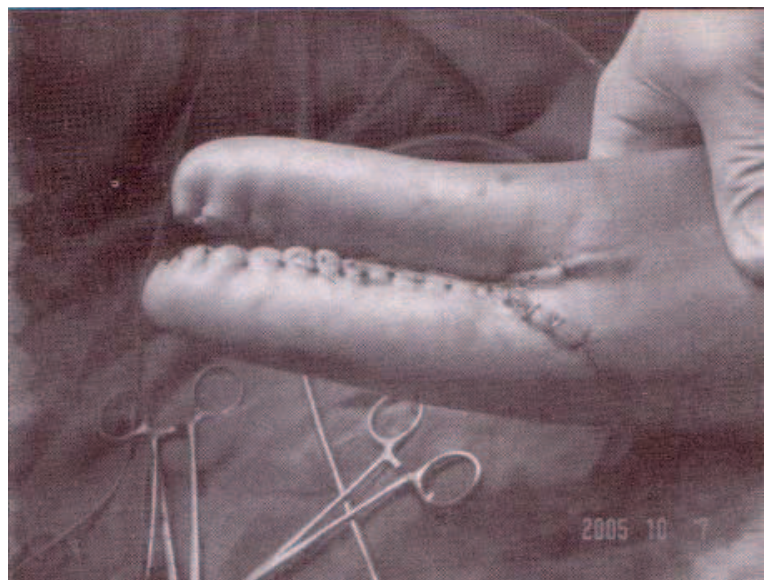

Fig.4. Per-operative picture 


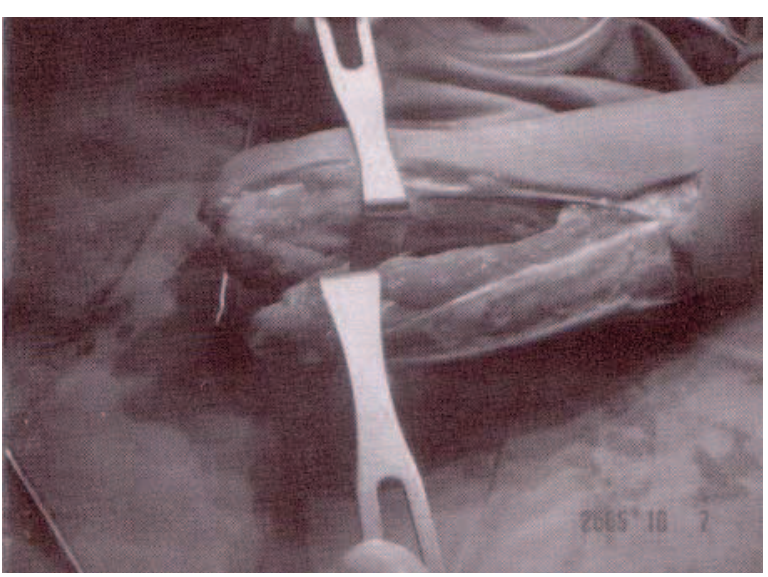

Fig. 5. After skin closure

Two musculocutaneous flaps with full thickness skin coverage on the opposing surfaces of the pincer were created. ${ }^{2,6,7}$

Debulking of the muscles was done whenever needed, but some muscle part was left intact for better function. The adductor muscles conserved are pronator teres, flexor carpi radialis and the extensor carpi ulnaris. The abductors conserved are brachioradialis, extensor carpi radials longus and brevis and flexor carpi ulnaris. Radius and ulna were separated by incising the interosseous membrane along the ulnar border. ${ }^{2,5,7}$

The reconstructive part of the procedure is done after the release of the tourniquet and after careful haemostasis. The muscles are reinserted at the tip of the stump and the sensitive skin flaps are fixed on the inside of the grip, the seizing area thus allowing tactile sensibility. Skin graft was not needed and the operating time was about 3 hours per operation. ${ }^{1,2,5,7}$

Three weeks after the surgery, physiotherapy programme was started, first mobilization of the pincer was done followed by grasping, feeding, ability to manage personal hygiene, ability to dress oneself and other manual activities like writing, painting etc. was taught which was continued for 03 months.

Grasp strength was assessed by asking the patient to hold against gravity, an empty, half full or full one liter plastic bottle of water and the grading was done as + (poor) ++ (Medium), +++ (good) and ++++ (excellent). Feeding with spoon and drinking out of a cup without help was also tested. Other functions tested after 03 months of
MANAGEMENT OF DOUBLE HAND AMPUTEES WITH KRUKENBERG PROCEDURE, K.C.BR; Chand P; Joshi A; Thapa BB; Joshi A physiotherapy \& training were, ability to brush their teeth, comb hair and shave and dress themselves which was assessed by asking the patient to use a zip fitted with a ring, to fasten and unfasten large buttons, to put on and take off T-shirt and to put on trousers.

Risk of functional failure is low if the procedure is done properly, this procedure however met with little interest in the western world mainly because of psychological rejection. The bifid forearm appears ugly to look at. In less developed countries like ours gaining a measure of self sufficiency takes procedure over the aesthetic aspect.

\section{RESULTS}

FromAugust2001 to April2006, five Krukeberg procedures in three patients were carried out. Two had bilateral hand amputation and one had left hand amputated with severely crushed right hand with amputated phalanges. Two patients were serving soldiers and one was a civilian boy 16 years of age. All three patients had successful procedures and no skin graft was needed; wound healing was good with no complications.

All three were kept in hospital for three months. Three weeks after surgery, physiotherapy

was started; first mobilization of the pincers followed by other activities of daily living like grasping, feeding, dressing and personal hygiene and writing. All could grasp, feed and dress themselves after three months of training and were discharged. The result was graded in four points; 1 for poor, 2 for satisfactory, 3 for good and 4 for excellent. A follow up at six and nine months were done to assess the functional capabilities, which was satisfactory. (Figs 6-9)

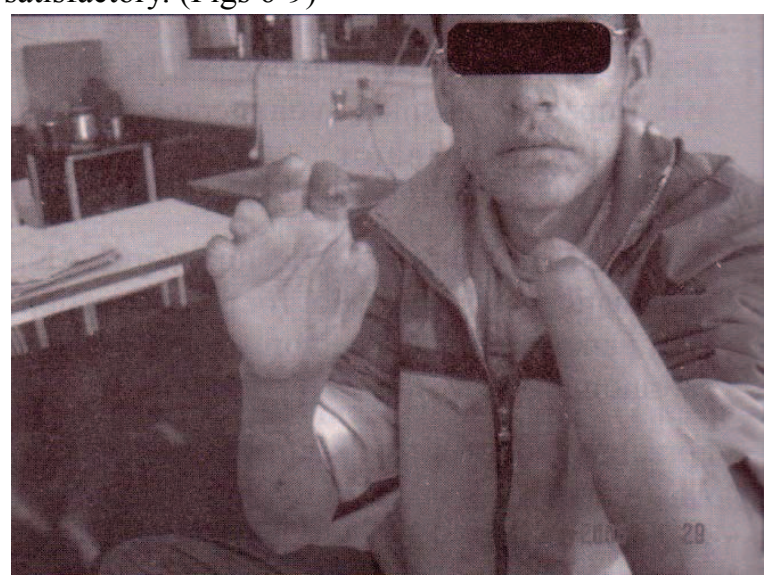

Fig. 6. Post-operative picture 


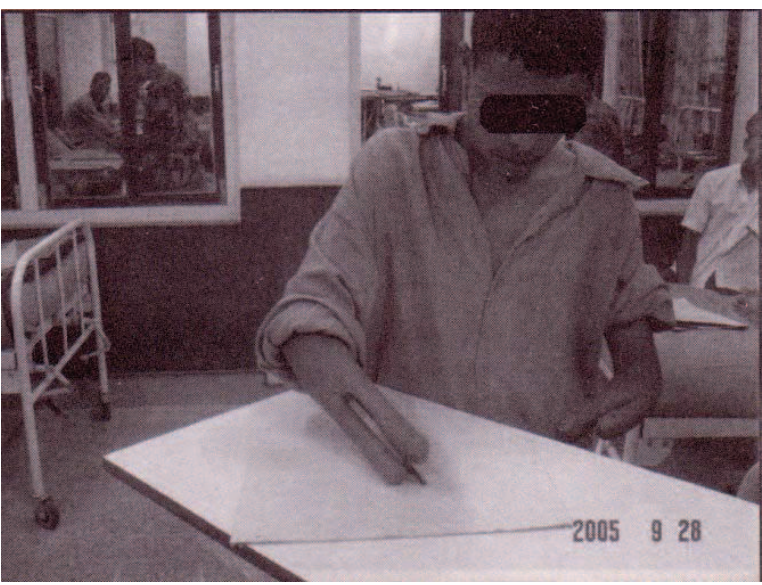

Fig. 7. Using pincer grasp for writing

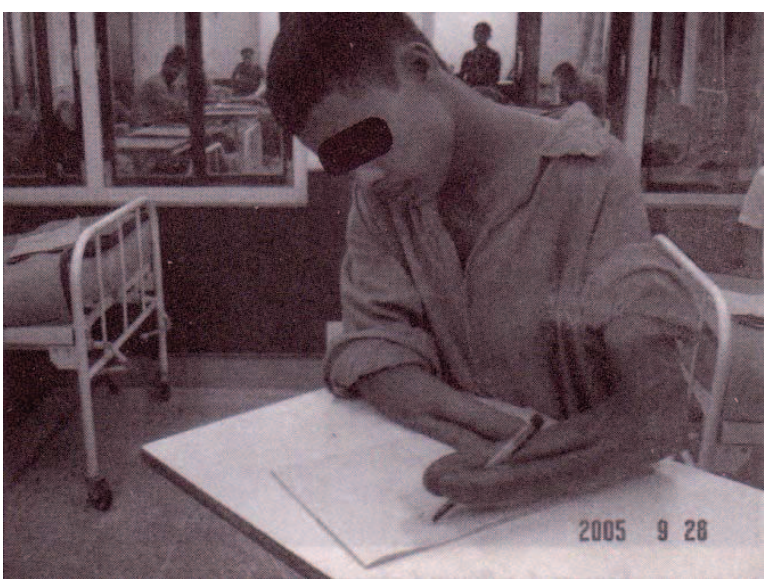

Fig. 8. Writing with left hand

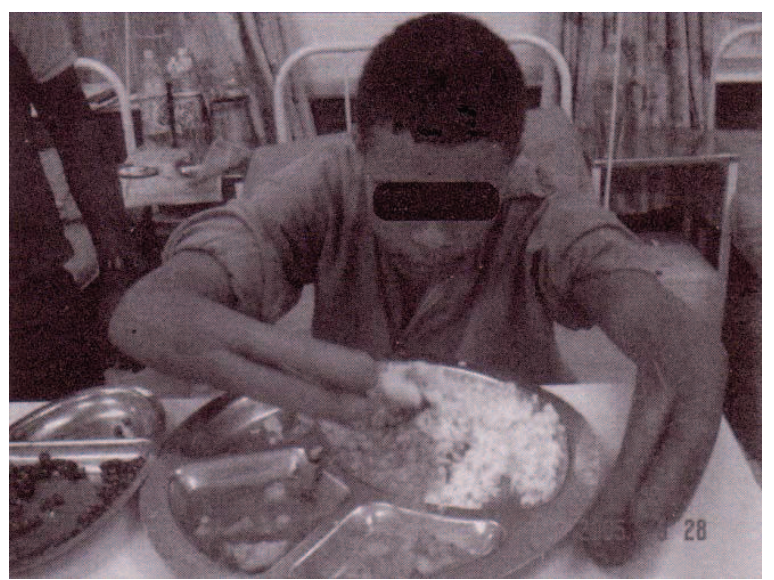

Fig. 9. ADL after Krukenberg operation

\section{DISCUSSION}

Amputation represents a major health and socioeconomic problem. In the west, vascular insufficiency and diabetes are the main causes while in our country, trauma seems to play a major role .Loss of hand results in loss of grasp and sensation. The higher the level of amputation the greater the functional loss. Loss of one hand results in severe handicap and this is multiplied with the loss of both hands. For the better outcome of the procedure, careful selection of the stump in terms of length, wound status and thorough counseling of the patient regarding the aesthetic value as well as the ultimate functional outcome should be discussed. Post operative physiotherapy along with functional training needs to be carried out diligently under supervision of the physiotherapist.

All three patients were prepared for the procedure after healing of the original wound. During their hospital stay the patients were counseled for the next step of management. They were shown photographs of the forearm after a similar surgery, so that they were mentally prepared to accept and try their best to make use of this ugly looking post-surgery forearm. Video clips were used showing use of the bifurcated forearm which really encouraged and prepared the patients for the procedure. A careful assessment of the patients' social environment, personality, and psychological state helps to select the patient because sometimes the bifurcated forearm just may not be acceptable and could be yet another psychological trauma. The operation provides forearm amputees with pincers which allow them to perform tasks without a prosthesis ,but does not preclude the use of any type of aid. ${ }^{8}$ The Krukenberg procedure of converting two non- functional below elbow stumps into sensitive and functional organs make makes the individual totally independent.

\section{CONCLUSION}

The result indicates that all three patients who were completely dependent on others could perform their ADL by themselves without much help from others. This self sufficiency has enabled them to survive. Though the number is small, we have yet to see the 
acceptability of the procedure if it is done in a large number of people. But in a poor country like ours where modern prosthesis are rare, this procedure is still useful to bilateral hand amputees.

Summary of functional results at follow-up of 6 and 9 months

\begin{tabular}{|c|c|c|c|c|c|c|}
\hline $\begin{array}{l}\text { Patients } \\
\text { No }\end{array}$ & $\operatorname{Sex}$ & Age & $\begin{array}{l}\text { Grasping } \\
\text { strength }\end{array}$ & Feeding & $\begin{array}{l}\text { Personal } \\
\text { hygiene }\end{array}$ & Dressing \\
\hline \multicolumn{7}{|c|}{ Double hand amputees operated on both sides } \\
\hline 1 & M & 25 & +++ & $3 / 4$ & $2 / 4$ & $3 / 4$ \\
\hline 2 & M & 16 & +++ & $3 / 4$ & $2 / 4$ & $3 / 4$ \\
\hline \multicolumn{7}{|c|}{ Single hand amputee with crushed other hand } \\
\hline 1 & M & 33 & +++ & $3 / 4$ & $3 / 4$ & $3 / 4$ \\
\hline
\end{tabular}

\section{REFERENCES}

1. Colp R, Rannsohoff NS. The Krukenberg stump. J Bone Joing Surg 1933;15:439-43.

2. Loosli-Guignard RM, Verdan C. Krukenberg's operation, indications and limitations. Ann Chir Main 1983;2:154-9.

3. Krukenberg H. Erfahrungen mit der Krukenberg hand. Arch Klin Chir 1931;165:191-201.

4. Lob A. Die Krukenberg-plastik in friedenszeiten. Hefte unfallheitkunde 1970;105:1-48.

5. Baumgartner R. Indikationsstellungen für die KrukenbergGreifhand aufgrund vonLangzeitergebnissen. Z orthos 1994;132:180-4.
6. Calandruccio JH. Amputations. In : Canale ST, Beaty JH, editors. Campbell's operative orthopaedics. 9th ed. Philadelphia (PA): Mosby;1998. p. 3517-47.

7. Tubiana R. Krukenberg's operation. Orthop Clin N Am 1981;12:55-61.

8. Garst RJ. The Krukenberg hand. J Bone Joint Surg 1991;73:385-8.

Dr Bachchu Ram K C

Email rehabnepal@gmail.com 